\begin{tabular}{|c|c|c|}
\hline Beitr. Ent. & Keltern & ISSN 0005-805X \\
\hline $\mathbf{5 7}(2007) 1$ & S. $93-104$ & 30.06 .2007 \\
\hline
\end{tabular}

\title{
Two new orchid bees of the subgenus Euglossella from Peru
}

\section{(Hymenoptera: Apidae)}

With 22 figures

\author{
I. A. Hinojosa-Díaz and M. S. Engel
}

\section{Summary}

Two new orchid bees of Euglossa subgenus Euglossella (Apinae: Euglossini) are described and figured from Peru. Both Euglossa (Euglossella) cosmodora sp. n. and E. (E.) urarina sp. n. belong to the decorata species group (i.e., the clade superficially resembling stingless bees of the genus Melipona) of Euglossella and are distinguished from their congeners as well as each other.

\section{Zusammenfassung}

Aus Peru werden zwei neue Prachtbienen-Arten der Gattung Euglossa, Subgenus Euglossella, (Apinae: Euglossini) beschrieben und dargestellt. Beide Arten, Euglossa (Euglossella) cosmodora sp. n. wie E. (E.) urarina sp. n., gehören der Euglossella-decorata-Gruppe an (ein Taxon, das oberflächlich an Stachellose Bienen der Gattung Melipona erinnert) und werden sowohl in der Gattung wie gegeneinander charakterisiert.

Keywords

Apoidea, Anthophila, Apinae, Euglossini, Peru, taxonomy

\section{Introduction}

Orchid bees (Euglossini) are an immediate favorite among apine Anthophila for their robust body sizes, frequently brilliant metallic colors, peculiar modifications (e.g., male metatibial structure, glossal elongation), and, of course, their close association with Orchidaceae. Among the species of the distinctive orchid bee subgenus Euglossella there is a clade of taxa comprising species that, due to their atypical setation and coloration, have a general resemblance to stingless bees of the genus Melipona (Meliponini). This assemblage, comprising Euglossa (Euglossella) decorata Sмiтн, E. (E.) singularis Mocsáry, and the recently described E. (E.) perpulchra Moure \& SCHLIndwein, is here referred by us as the decorata species group. Herein we provide the description of two new species of Euglossella from Peru belonging to the decorata group. Morphological terminology follows that of Engel (1999, 2001) and Michener (2000), with one, minor exception. Typically that structure termed the spiculum in most genera is herein referred to as the "notospiculum", noting that this process does not project anteriorly from the proximal (anterior) margin of the eighth metasomal sternum of the male as in typical bee genera. Instead, in Euglossini this minute process is roughly procurved and emanates as a projection of the anterior extreme of the dorsal sternal edge. A full account of the comparative morphology of male terminalia in Euglossini is in preparation by one 
of us (Hinojosa-Díaz, in prep.). Measurements are those of the holotype (when corresponding to the sex of the holotype), with measurements of paratypes noted in parentheses.

\section{Systematics}

Euglossa (Euglossella) cosmodora, sp. n. (Figs 1-12)

\section{Diagnosis:}

Both sexes with head mainly black, mesosoma metallic olive-green with dense fulvous setae; legs dark brown; metasoma metallic, golden olive-green, with a noticeably dark brown band on anterior half of second metasomal tergum bordered anteriorly and posteriorly by yellow streaks. Second metasomal sternum with two false slits almost converging mesally. Lateral lobes of posterior section of eighth metasomal sternum of male with lateral edge convex; incision between posterior and dorsal processes of gonocoxite forming an acute angle with posterior edge of dorsal process; gonostylus thumb-like.

\section{Description:}

$\sigma^{*}$ : Structure. Total body length $13 \mathrm{~mm}$; labiomaxillary complex in repose surpassing metasoma by $\sim 1 \mathrm{~mm}$ (Figs 1-2). Head length $3.31 \mathrm{~mm}$, width $5.15 \mathrm{~mm}$; upper interorbital distance $2.69 \mathrm{~mm}$; lower interorbital distance $2.38 \mathrm{~mm}$; upper clypeal width $1.27 \mathrm{~mm}$ (as measured between dorsolateral angles of clypeus); lower clypeal width $2.25 \mathrm{~mm}$ (as measured at level of lower lateral parts); clypeal protuberance $0.8 \mathrm{~mm}$ (following measurement method of BrooKs, 1988); medial and paramedial clypeal ridges sharp; labrum square (length and width $1.2 \mathrm{~mm}$ ) (Fig. 6); medial labral ridge sharp; paramedial labral ridges weak, oblique, present only in proximal one-half of labrum; labral windows ovoid, occupying proximal one-half of labrum; interocellar distance $0.31 \mathrm{~mm}$; ocellocular distance $0.84 \mathrm{~mm}$; length of first flagellar article $(0.5 \mathrm{~mm})$ equal to combined lengths of second and third flagellar articles $(0.5 \mathrm{~mm})$; length of malar area $0.22 \mathrm{~mm}$. Mandible tridentate, mid-tooth smaller, basalmost tooth (in dorsal position) forming angle of $\sim 120^{\circ}$ with other two teeth. Pronotal lateral angle acute; intertegular distance $4 \mathrm{~mm}$; mesoscutal length $3.1 \mathrm{~mm}$; mesoscutellar length $1.46 \mathrm{~mm}$; posterior border of mesoscutellum evenly convex (Fig. 1); mesotibial length $2.5 \mathrm{~mm}$; mesobasitarsal length $2.73 \mathrm{~mm}$, width $0.73 \mathrm{~mm}$ (as measured at proximal posterior keel); metatibia triangular, maximum thickness $1.42 \mathrm{~mm}$; metatibial anterior border length $4 \mathrm{~mm}$, ventral border length $2.55 \mathrm{~mm}$, dorso-posterior border length $5.05 \mathrm{~mm}$, not noticeably divided in two sections by dorsal section of metatibial organ slit; metatibial ventroposterior angle semi-acute; metatibial organ slit dorsal and outer sections well defined with a junction narrower than contiguous width of dorsal section; outer section of metatibial organ slit lanceolate, maximum width occupying about one-third of metatibial outer surface width (as viewed at same level), anterior edge strongly convex (Fig. 7); dorsal section of metatibial organ slit rhomboid, length $0.72 \mathrm{~mm}$; metabasitarsal length $2.65 \mathrm{~mm}$, mid-width $0.91 \mathrm{~mm}$; metabasitarsal ventral border only slightly projected on its posterior two-thirds, posterior angle orthogonal, rounded; basal and distal teeth of pretarsal claws parallel, separated by deep and narrow cleft; basal tooth slightly shorter. Forewing length $10.23 \mathrm{~mm}$; jugal comb with 13-14 blades; hind wing with 23 hamuli. Maximum metasomal width $5.46 \mathrm{~mm}$; second metasomal sternum with two domelike protuberances, each rising evenly from central disc and posteriorly ending in a sharp concave edge, slightly excavate as "false" slits or cowls (slits or cowls, sensu Roubiк, 2004), both almost converging mesally. 
Coloration. Head mainly black (except as described below), with some green-cyan hue on midclypeus, paraocular areas, and more noticeably on gena; paraocular ivory marks well developed, triangular, with a brief notch on area where they encounter antenno-ocular sulci, lower width equals half of length of lower lateral parts of clypeus; lower lateral parts of clypeus ivory, ambertranslucent at edge; labrum ivory; labral anterior and posterior edges as well as labral windows amber-translucent; malar area brown on sides, ivory at center; mandible ivory on basal outer surface, teeth and ridges brown; antenna brown, lighter on posterior surface of flagellum; scape with ivory spot covering about three-quarters of anterior surface (Fig. 6). Prothorax, mesoscutum, most of mesoscutellum, and propodeum metallic olive green with strong bronze highlights; posterior edge of mesoscutellum light brown; remainder of mesosoma metallic bronze with green highlights (Figs 1-2); legs dark brown, distalmost pro- and mesotarsomere, as well as all pretarsal claws slightly lighter (except distal half dark brown); olive green highlights intermixed with some bronze highlights on all coxae, trochanters, tibiae (noticeably metatibia), and basitarsi (Figs 2, 7); tegulae and wings uniformly light amber, hyaline, with light golden hue (Figs 1-2). Antero-lateral corners of first metasomal tergum dark brown, postero-lateral edges brown, remainder yellow; anterior half of second metasomal tergum with a brown band that becomes darker and wider laterally, followed mesally by a narrow yellow streak, posterior edge with a golden, olive-green band; third through sixth metasomal terga brown laterally, remainder metallic golden olivegreen; seventh metasomal tergum black; posterior border of second through sixth metasomal terga slightly translucent; all terga with some metallic green highlights (Fig. 1). Sterna yellowish except fourth metasomal sternum mainly dark brown, all with some metallic green highlights, and posterior sections translucent.

Sculpturing. Frons, supraclypeal area, upper section of antennal depressions and clypeus areolate, with dense, strong punctures, especially large between paramedial ridges of clypeus and upper section of antennal depressions (Fig. 6); paraocular areas less densely sculptured, punctures shallow; vertex moderately punctate, smooth on anterior area to ocellar monticule; gena moderately punctate, smooth on a narrow streak close to compound eye (except for some large punctures on upper section). Mesosoma with round, moderately-dense punctures, separated by about one puncture diameter centrally on mesoscutum and around three diameters on mesepisternum; metatibia moderately dense punctate on proximal area, becoming gradually smooth towards ventral border and contiguous area to metatibial organ slit (Fig. 7). Antero-mesal section of first metasomal tergum smooth, remaining terga and all sterna imbricate-punctate, punctures shallow, medium-sized, and moderately dense, on anterior sections of both terga and sterna, becoming smaller, denser, and slightly stronger posteriorly, in a shingle-like arrangement.

Vestiture. Frontal fringe setae moderately dense, dark brown and fulvous, long (longest $-1 \mathrm{~mm}$ ), erect, minutely branched; vertex with setae of same nature as frontal fringe, except mainly fulvous (some dark close to compound eyes) concentrated laterally towards preoccipital ridge, some on interocellar area; preoccipital ridge with a mixture of similar fulvous setae and pale, shorter, denser and noticeably plumose setae; antennal depressions with moderately-dense, fulvous, plumose setae; paraocular areas with scattered whitish setae otherwise like those of frontal fringe; clypeus and labrum with scattered, brown, short, simple setae intermixed with minute whitish setae; malar area with scattered, whitish, minute, simple setae; anterior surface of mandible as on malar area, ventral surface with scattered, brown, long, erect, simple setae; gena with dense, short, whitish, plumose setae, increasing in length and becoming darker towards lower section; antenna with pale, short, simple setae, longer and scattered on scape and denser on flagellum (Figs 1-2, 6). Mesosoma covered with dense, fulvous, moderately long, plumose setae, becoming lighter on pleural and ventral areas; proximal podites (mainly coxae, trochanters, and part of femora) with setae as on 

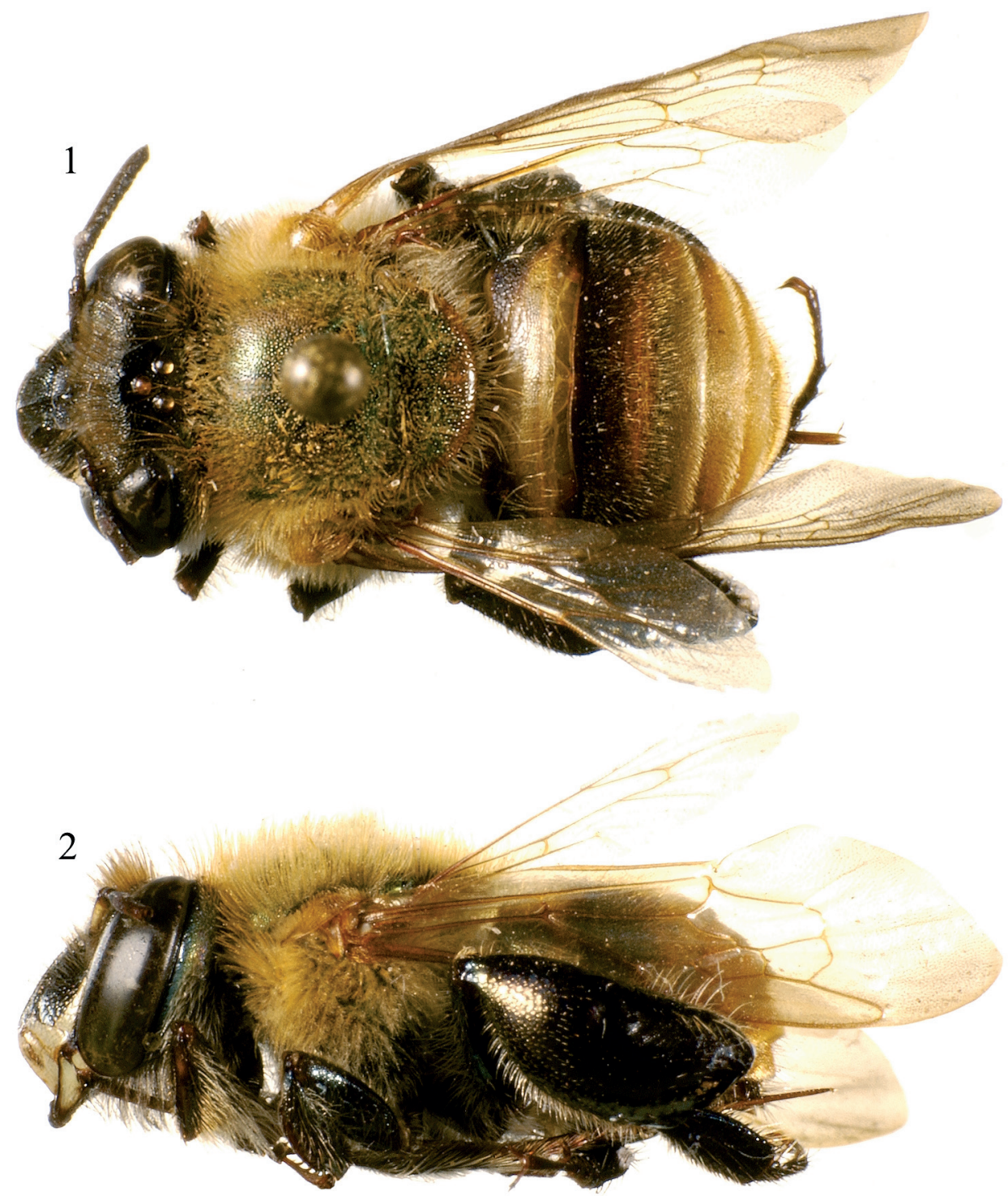

Figs 1-2: Euglossa (Euglossella) cosmodora sp. n., male holotype. - 1 dorsal habitus. - 2 lateral habitus.

ventral part of mesosoma (Figs 1-2); fulvous, simple, setae on femora (except as previously noted), tibiae (exceptions noted hereafter), and outer surface of tarsal articles; chemical gathering tufts on second through fourth protarsomeres made of dense, brown, long, setae; inner surfaces of probasitarsus, meso- and metatarsomeres with dense, dark brown, sturdy setae; mesotibia with two proximal tufts, anterior tuft rhomboid, about one-third as long as velvety area, posterior tuft oblong, about one-third as long as major axis of anterior tuft, both tufts made of fulvous setae directed posteriad; mesobasitarsus with three major wavy setae and two secondary setae (half as thick as the major setae) on inner surface right after proximal keel, all brown [these setae were 

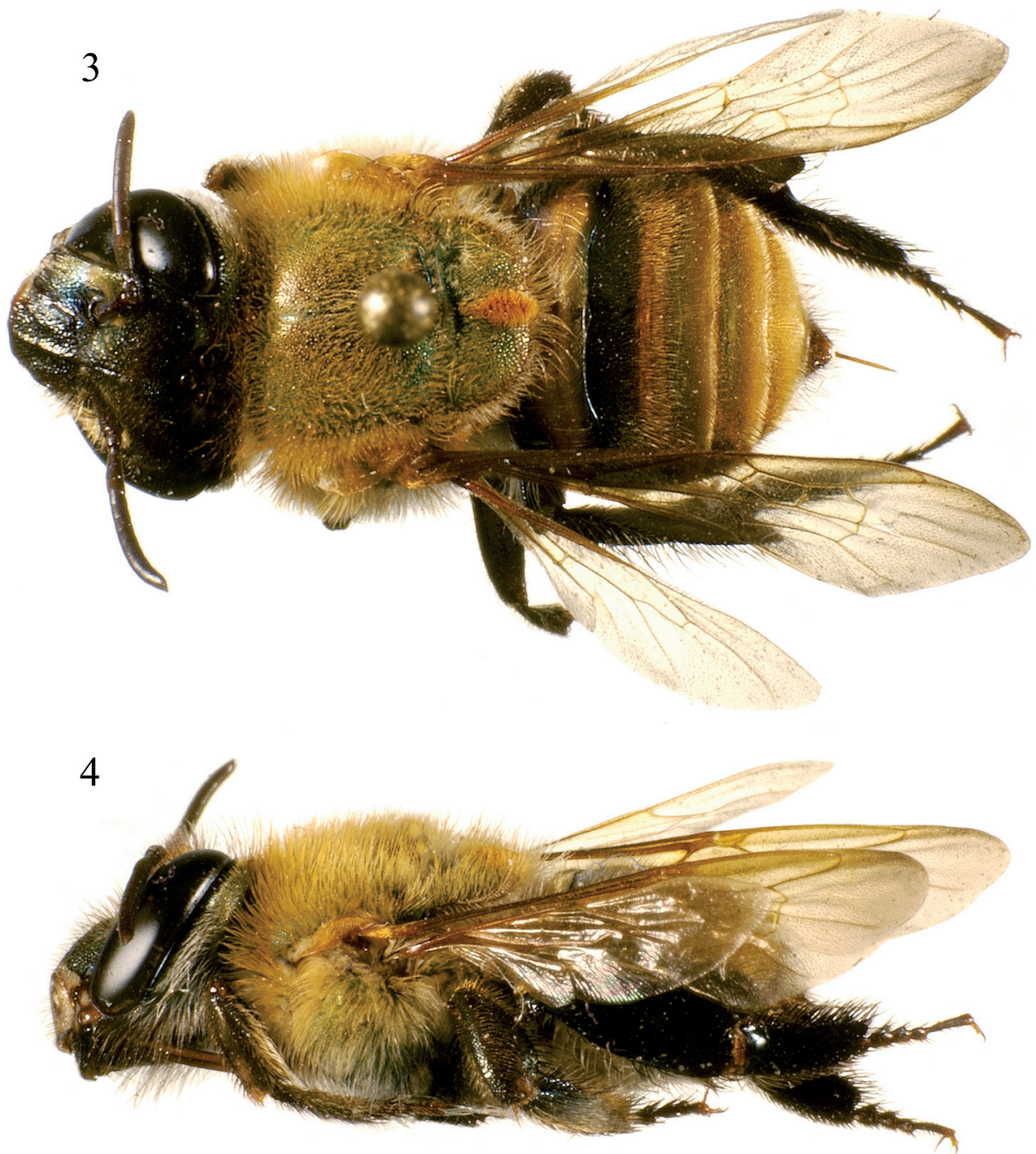

Figs 3-4: Euglossa (Euglossella) cosmodora sp. n., female paratype. -3 dorsal habitus. -4 lateral habitus (right side of bee photographed and then reversed in order to place anterior of bee at left of photograph).

termed catharotrichia ("cleaning hairs") by Moure \& SCHLindwein, 2002; however, the function of these setae is not well known so we have not employed this term]; metatibia with longer setae on anterior border and distal half of dorso-posterior border, outer surface with scattered, brown, short, erect setae, bare on contiguous depression to metatibial organ; metatibial organ slit closed with dark brown setae (Fig. 7). Metasoma covered with golden-fulvous, simple setae, moderately dense, long and erect on sterna, and antero-lateral corners and anterior border of first metasomal tergum; second through fifth metasomal terga with posterior bands of dense, golden-fulvous, appressed setae (Fig. 1); scattered, dark brown, short, erect setae on sides of second through sixth metasomal terga; false slits of second metasomal sternum with patches of dense, fulvous, long setae, directed posteriorly reaching posterior edge of sternum. 

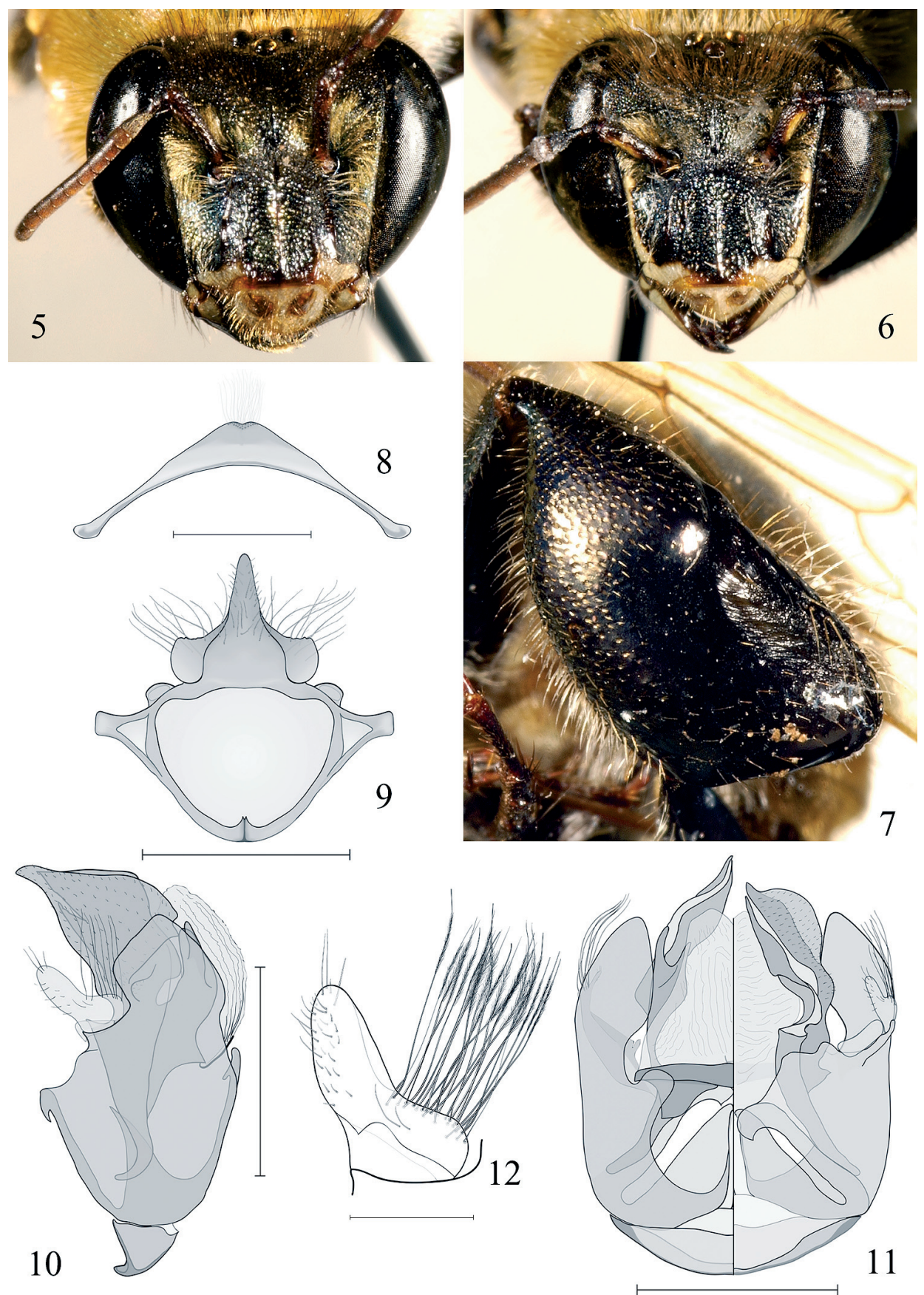

Figs 5-12: Euglossa (Euglossella) cosmodora sp. n. -5 facial aspect of female holotype. -6 facial aspect of male paratype. -7 outer surface of male metatibia. -8 male seventh metasomal sternum, ventral aspect. -9 male eighth metasomal sternum, dorsal aspect. 10 - male genitalic capsule, lateral aspect. - 11 male genitalic capsule, left half dorsal aspect, right half ventral aspect. -12 detail of male gonostylus, lateral aspect. Scale bars $=1.0 \mathrm{~mm}$ except that for figure 12 is $0.25 \mathrm{~mm}$. 
Terminalia. Posterior margin of seventh metasomal sternum invaginated mesally, forming a shallow incision with converging sides forming an angle of $\sim 120^{\circ}$, lateral sections almost straight except for a slight protuberance; apical setae on invaginated section missing (however, this could just be an artifact of our preparation treatment as the alveoli are present indicating the once presence of setae, the position of which are indicated in Fig. 8). Anterior section of eighth metasomal sternum wider than long (not considering apodemes); notospiculum slightly divided apically; posterior section of eighth metasomal sternum projected ventrally making an angle of $\sim 110^{\circ}$ in respect to anterior section; lateral lobes of posterior section of eighth metasomal sternum with lateral edge convex, long plumose setae inserted mainly on ventral surface of lobes; mid-posterior process acute, with scattered simple setae (some plumose setae at base) on both dorsal and ventral surfaces, becoming shorter towards apex (Fig. 9). Anterior-most section of gonobase projected ventrally forming an angle of $\sim 80^{\circ}$ with remainder of ventral edge (Fig. 10). Dorsal process of gonocoxite as wide as long; incision between posterior and dorsal processes of gonocoxite forming an acute angle with posterior edge of dorsal process (Fig. 11). Gonostylar shape thumb-like, as shown in figure 12; gonostylar setae on basal section long, and plumose in their apical halves.

o : Structure. Total body length $13.07-13.15 \mathrm{~mm}$; labiomaxillary complex in repose reaching end of metasoma. Head length $3.7 \mathrm{~mm}$; head width $5.15 \mathrm{~mm}$; upper interorbital distance $2.8 \mathrm{~mm}$; lower interorbital distance $2.54 \mathrm{~mm}$; upper clypeal width $1.31 \mathrm{~mm}$; lower clypeal width $2.29 \mathrm{~mm}$; clypeal protuberance $0.73-1.02 \mathrm{~mm}$; medial clypeal ridge sharp, paramedial ridge sharp on lower half; labrum square (length and width $1.2 \mathrm{~mm}$ ); labral ridges and windows as in male; anterior edge of labrum arched outwards; interocellar distance $0.36 \mathrm{~mm}$; ocellocular distance $0.87 \mathrm{~mm}$; length of first flagellar article $(0.5 \mathrm{~mm})$ equal to combined lengths of second and third flagellar articles $(0.5 \mathrm{~mm})$; length of malar area $0.25 \mathrm{~mm}$. Mandible tridentate, mid-tooth smaller, basal tooth broader than other two teeth. Pronotal lateral angle orthogonal; intertegular distance $3.8 \mathrm{~mm}$; mesoscutal length $2.98 \mathrm{~mm}$; mesoscutellar length $1.45 \mathrm{~mm}$; posterior border of mesoscutellum evenly convex (Fig. 3); mesotibial length $2.55 \mathrm{~mm}$; mesobasitarsal length $2.33 \mathrm{~mm}$, maximum width $0.73 \mathrm{~mm}$; metatibia triangular; metatibial anterior border length $3.45 \mathrm{~mm}$; metatibial ventral border length $2.04 \mathrm{~mm}$; metatibial dorso-posterior border length $4 \mathrm{~mm}$; metatibial ventro-posterior angle semi-acute; basal tooth of pretarsal claws slightly divergent of distal tooth, comparatively shorter (half length of distal tooth). Forewing length $10.3 \mathrm{~mm}$; hind wing with 21-25 hamuli. Maximum metasomal width $5.08 \mathrm{~mm}$.

Coloration. As described for male except as follows: paraocular marks absent; ivory coloration on mandible restricted to proximal one-third (Fig. 5); mesotibia with a yellow triangular spot on ventro-posterior angle.

Sculpturing. As described for male except metepisternum and propodeum minutely imbricate.

Vestiture. As described for male except as follows: mesoscutellar patch rhomboid, composed of dense, fulvous, erect, thick, multibranched (branches minute) setae (Fig. 3). Mesotibia with a streak of spur-like, dark brown setae on posterior and ventral edges; metatibial corbicula surrounded by long, dark brown setae. Mesal sections of all sterna nearly bare (where labiomaxillary complex resides when in repose).

\section{Type material:}

Holotype (Figs 1-2): ơ labeled, "PERU: Junín Dept. Villa-Oxapampa Rd. 1200 m 1045'36" S, 75²1'30" W, 18 OCT 1999; R. Brooks, PERU 1B99 056, ex: on red flowering 'Zauschneria like' // Euglossa singularis Mocsáry, det. R.W. Brooks”. The holotype is in the Division of 
Entomology, University of Kansas Natural History Museum, Lawrence, Kansas, USA. Paratypes: o (Figs 3-4), same label data as holotype, deposited in the Division of Entomology, University of Kansas Natural History Museum; ㅇ labeled, "Valle Chanchamayo (Peru), 800 m, 5.2.1939 [handwritten, 5 February 1939], leg. Weyrauch // decorata", deposited in Departamento de Zoologia, Universidade Federal do Paraná, Curitiba, Paraná, Brazil. The holotype is in excellent condition except missing the left flagellum beyond the fourth flagellar article, while the Kansas paratype is missing the left mesotarsus and distal part of the mesotibia.

\section{Etymology:}

The specific epithet is a reference to the striking beauty of this bee species (Greek, kosmos, meaning "universe", and doron, meaning "gift": literally meaning, "gift to the universe").

\section{Euglossa (Euglossella) urarina, sp. n. (Figs 13-22)}

\section{Diagnosis:}

Head integument metallic, dark green with bronzy-golden highlights, mesosoma metallic green with dense fulvous setae; legs brown, yellow-amber on two proximal podites; metasoma metallic, golden olive-green, first metasomal tergum and anterior half of second metasomal tergum yellow. Lateral lobes of posterior section of eighth metasomal sternum of male with lateral edge straight; posterior invagination of seventh metasomal sternum forming an incision with sides converging in orthogonal angle; incision between posterior and dorsal processes of gonocoxite forming an orthogonal angle with posterior edge of dorsal process; gonostylus with a prominent secondary "hump" dorsal to main thumb-like projection.

\section{Description:}

$\sigma^{\star}$ : Structure. Total body length $12 \mathrm{~mm}$. Labiomaxillary complex at least reaching metasomal apex in repose (Fig. 14). Head length $3.15 \mathrm{~mm}$, width $4.77 \mathrm{~mm}(4.96 \mathrm{~mm})$; upper interorbital distance $2.31 \mathrm{~mm}(2.38 \mathrm{~mm})$; lower interorbital distance $2.08 \mathrm{~mm}(2.12 \mathrm{~mm})$; upper clypeal width $1.09 \mathrm{~mm}(1.13 \mathrm{~mm})$; lower clypeal width $1.98 \mathrm{~mm}(2.05 \mathrm{~mm})$; clypeal protuberance $0.62 \mathrm{~mm}$; clypeal ridges as in E. cosmodora; labrum square (length and width $1.15 \mathrm{~mm}$ ); labral ridges and windows as in E. cosmodora; interocellar distance $0.29 \mathrm{~mm}$; ocellocular distance $0.69 \mathrm{~mm}(0.72 \mathrm{~mm})$; first flagellar article $[0.43 \mathrm{~mm}(0.51 \mathrm{~mm})]$ equal to combined lengths of second and third flagellar articles $[0.43 \mathrm{~mm}(0.51 \mathrm{~mm})]$; length of malar area $0.15 \mathrm{~mm}$. Mandibular dentition as in E. cosmodora. Pronotal lateral angle acute; intertegular distance $3.45 \mathrm{~mm}(3.63 \mathrm{~mm})$; mesoscutal length $2.62 \mathrm{~mm}$ (2.76); mesoscutellar length $1.38 \mathrm{~mm}$; posterior border of mesoscutellum evenly convex (Fig. 15); mesotibial length $2.44 \mathrm{~mm}$; mesobasitarsal length $2.58 \mathrm{~mm}$, width $0.73 \mathrm{~mm}$; metatibia triangular, maximum thickness $1.13 \mathrm{~mm}$; metatibial anterior border length $3.64 \mathrm{~mm}$, ventral border length $1.82 \mathrm{~mm}$, dorso-posterior border length $4.25 \mathrm{~mm}$, not noticeably divided in two sections by dorsal section of metatibial organ slit; metatibial ventro-posterior angle semi-acute; metatibial organ slit dorsal as in E. cosmodora, except maximum width occupying about one-fourth of metatibial outer surface width, and dorsal section length $0.69 \mathrm{~mm}$ (Fig. 17); metabasitarsal length $2.36 \mathrm{~mm}(2.69 \mathrm{~mm})$, mid-width $0.84 \mathrm{~mm}$ $(0.91 \mathrm{~mm})$; metabasitarsal ventral border and pretarsal claws as in E. cosmodora. Forewing length $9.46 \mathrm{~mm}(10 \mathrm{~mm})$; jugal comb with 13-15 blades; hind wing with 21-23 hamuli. Maximum metasomal width $4.77 \mathrm{~mm}$ (4.92 $\mathrm{mm})$; second metasomal sternum evenly protuberant mesaly, not excavated. 


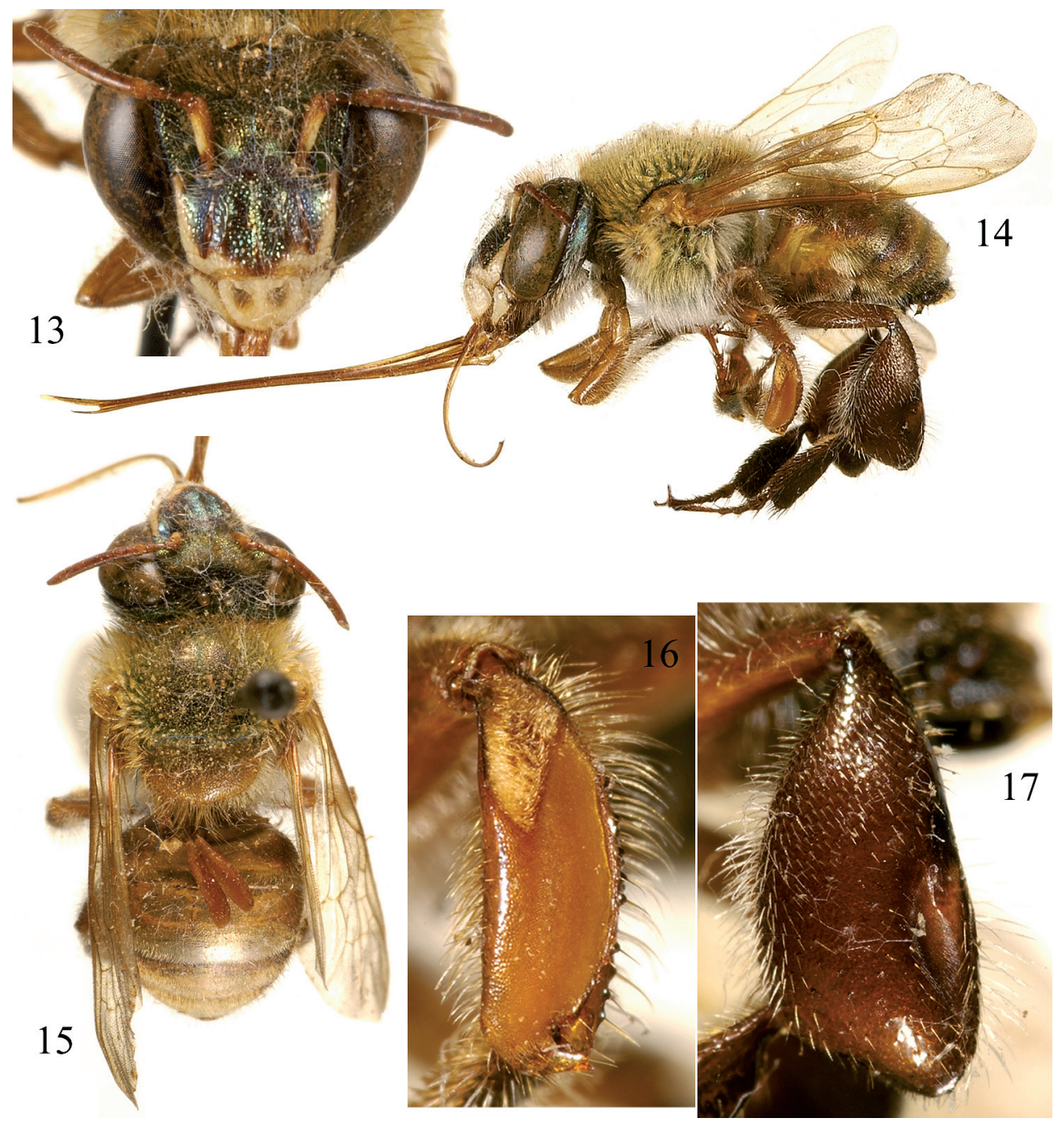

Figs 13-17: Euglossa (Euglossella) urarina sp. n., male holotype. - 13 facial aspect. - 14 lateral habitus. - 15 dorsal habitus. -16 outer surface of mesotibia. - 17 outer surface of metatibia.

Coloration. Head mainly metallic dark green (except as described below), with bronzy-golden highlights specially on interantennal area and antennal depressions; clypeal ridges and edges brown, brown on anterior half of vertex and narrow genal streak bordering compound eye; paraocular ivory marks as in E. cosmodora, except lower width equals three quarters of length of lower lateral parts of clypeus; lower lateral parts of clypeus, labrum, malar area and mandibles as in E. cosmodora; antenna brown; scape with ivory spot covering most of anterior surface (Fig. 13). Most of mesosoma metallic green with strong bronzy highlights (particularly on center of mesoscutum); anterior half of prothorax and anterior flattened sections of mesepisternum brown; posterior two thirds of mesoscutellum amber (Figs 14-15); legs brown, yellow-amber on two proximal podites; pretarsal claws slightly lighter, distal half dark brown; faint bronzy-green highlights on all legs specially on proximal podites (Figs 14, 16-17). First metasomal tergum amber-yellow mesally, lateral edges and posterior narrow streak brown; second metasomal tergum 
similar to first but with a broad metallic olive-green, golden posterior band; third through sixth metasomal terga brown with posterior golden, olive-green band; seventh metasomal tergum brown not banded; posterior border of second through sixth metasomal terga slightly translucent (Figs 14-15). First and second metasomal sterna yellowish; remaining sterna brown, mesally with posterior sections translucent.

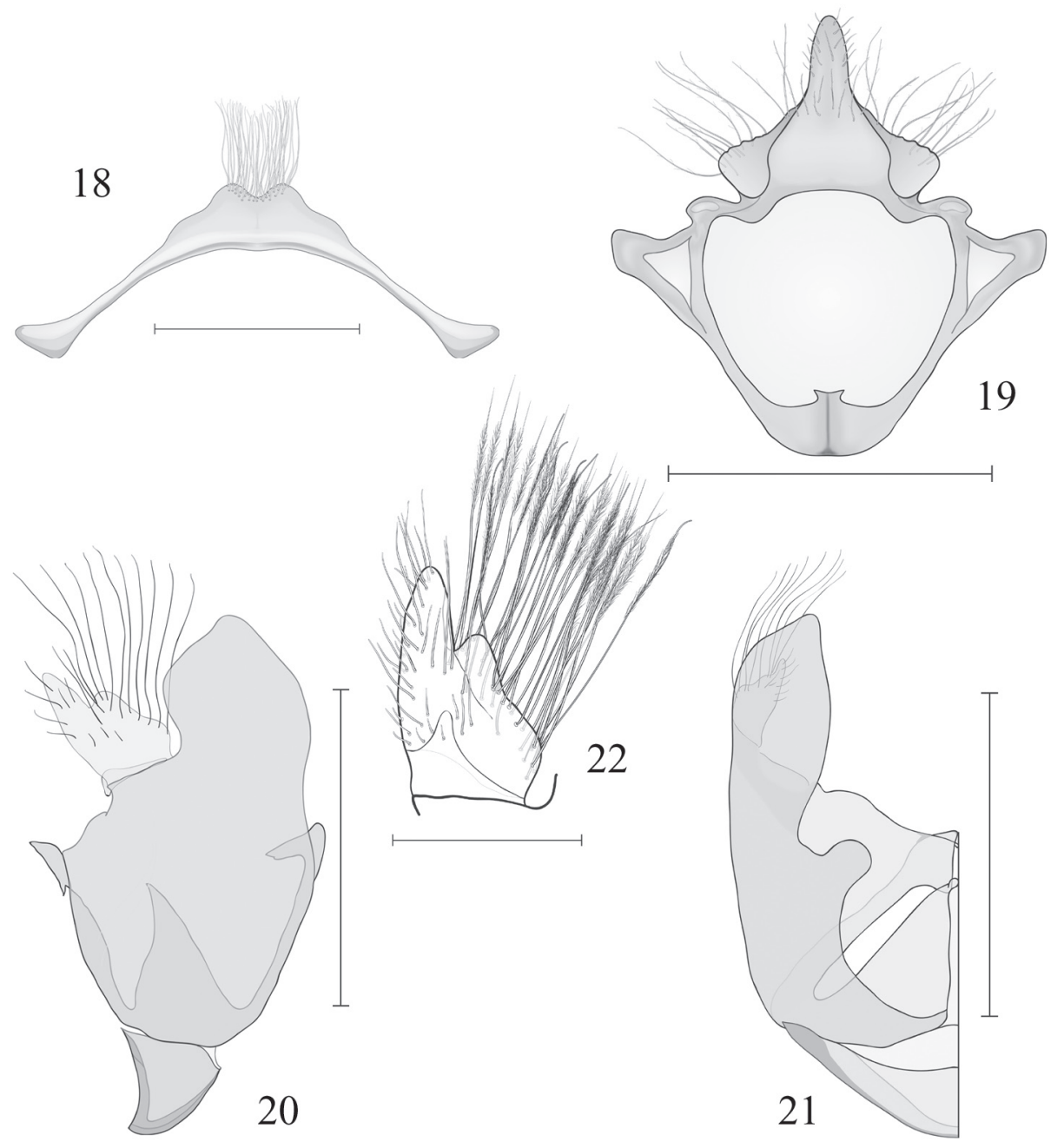

Figs 18-21: Euglossa (Euglossella) urarina sp. n., male holotype. - 18 seventh metasomal sternum, ventral aspect. - 19 eighth metasomal sternum, dorsal aspect. -20 lateral aspect of genitalic capsule (penis valves and aedeagus omitted as they do not differ from E. cosmodora). -21 dorsal aspect of genitalic capsule (penis valves, aedeagus, and ventral aspect omitted as they do not differ from E. cosmodora). -22 detail of gonostylus, lateral aspect. Scale bars $=1.0 \mathrm{~mm}$ except that for figure 22 is $0.25 \mathrm{~mm}$.

Sculpturing. Head sculpturing basically as described for E. cosmodora except smooth areas of vertex restricted to nearest area around ocelli. Mesosoma (including legs) and metasoma as in E. cosmodora. 
Vestiture. Head vestiture as in E. cosmodora. Mesosoma basically as in E. cosmodora except slightly lighter coloration of all setae and other notations as follows: mesotibial tufts made of light fulvous setae; anterior tuft rhomboid, about half as long as velvety area, posterior tuft ovoid, about onefourth as long as major axis of anterior tuft (Fig. 16); mesobasitarsus with three wavy setae (no secondary wavy setae evident); setae on metatibial outer surface light otherwise as in E. cosmodora; metatibial organ slit closed with fulvous setae, becoming brown on dorsal section (Fig. 17). Metasomal vestiture as in E. cosmodora.

Terminalia. Posterior margin of seventh metasomal sternum invaginated mesally, forming a moderately deep incision with converging sides forming an almost orthogonal angle, lateral sections with a noticeable protuberance; apical setae on invaginated section as long as mesal length of sternum (Fig. 18). Eighth metasomal sternum as in E. cosmodora, except for lateral lobes of posterior section with lateral edge straight (Fig. 19). Anterior-most section of gonobase just slightly projected ventrally (not bent) (Fig. 20). Gonocoxite as in E. cosmodora, except for incision between posterior and dorsal processes forming an orthogonal angle with posterior edge of dorsal process (Fig. 21). Gonostylus with a prominent secondary "hump" dorsal to main thumb-like projection (Fig. 22).

\section{१: Unknown.}

\section{Variation:}

The specimen designated as paratype, besides the variation in measurements noted in parentheses in the description, has a slightly darker coloration, both in integument and vestiture.

\section{Type material:}

Holotype (Figs 14-15): 0", labeled, "Iquitos Peru // 8 Sept 64; C H Dodson // On Gongora maculata 2734 // E. decorata Smith" [first three labels handwritten]. The holotype is in the Florida Museum of Natural History, University of Florida, USA. The holotype has the labiomaxillary complex incomplete (the main part of it, as shown in Fig. 14, fell off the specimen), hyphae covering the head and parts of the mesosoma and metasoma. Paratype: $\sigma^{*}$, labeled, "Iquitos Peru // H Moore [unintelligible handwriting] // Gon. maculata" [all labels handwritten]. The paratype is deposited in the Division of Entomology, University of Kansas Natural History Museum, Lawrence, Kansas, USA. The paratype is missing the right antenna (scape and pedicel glued to a point), left foreleg, and tibia and tarsomeres of midleg. Although the head of the paratype and right midleg are glued to the mesosoma (representing repair of some disarticulation in the past by an unknown individual), we are confident that both are correctly associated with the specimen.

\section{Etymology:}

The specific epithet is a reference to the Urarina, indigenous people inhabiting the Peruvian Amazon in Loreto Department and where the type material was collected. The name is treated as a noun in apposition.

\section{Floral records:}

Holotype and paratype bear labels referring to the plant where they were presumably collected, this being Gongora maculata LinDL. (Orchidaceae) for both. The holotype specimen has, attached to the posterior edge of the mesoscutellum, a complete pollinium and remnants of another, both belonging to orchids of the genus Gongora (R. L. Dressler, pers. com.) (Fig. 15). 


\section{Acknowledgements}

Partial support was provided by U.S. National Science Foundation grant EF-0341724 (to M. S. ENGEL) and a Guggenheim Fellowship from the John Simon Guggenheim Memorial Foundation (to M. S. ENGEL) while a fellowship from Consejo Nacional de Ciencia y Tecnología (CONACYT) supported the work of the senior author. The senior author is grateful to Dr. N. H. Williams for loaning the specimens of E. urarina and to Dr. G. A. R. Melo for loaning a specimen of E. cosmodora. Dr. R. L. Dressler (through P. Protti) provided the identification of the orchid pollinaria on the holotype of E. urarina. This is contribution No. 3475 of the Division of Entomology, University of Kansas Natural History Museum.

\section{References}

BRooks, R. W. 1988: Systematics and phylogeny of the anthophorine bees (Hymenoptera: Anthophoridae; Anthophorini). - University of Kansas Science Bulletin 53 (9): 436-575.

EngeL, M. S. 1999: The first fossil Euglossa and phylogeny of the orchid bees (Hymenoptera: Apidae; Euglossini). - American Museum Novitates 3272: 1-14.

EngeL, M. S. 2001: A monograph of the Baltic amber bees and evolution of the Apoidea (Hymenoptera). - Bulletin of the American Museum of Natural History 259: 1-192.

Michener, C. D. 2000: The Bees of the World. - Pp. xiv+[i]+913, 16 pls. - Baltimore: Johns Hopkins University Press.

Moure, J. S. \& Schlindwein, C. 2002: Uma nova espécie de Euglossa (Euglossella) Moure do Nordeste do Brasil (Hymenoptera, Apidae). - Revista Brasileira de Zoologia 19 (2): 585-588.

Roubiк, D. W. 2004: Sibling species of Glossura and Glossuropoda in the Amazon Region (Hymenoptera: Apidae: Euglossini). - Journal of the Kansas Entomological Society 77 (3): 235-253.

\section{Authors' address:}

Mr. I. A. Hinojosa-Díaz and Prof. Dr. M. S. Engel

Division of Entomology (Paleoentomology)

Natural History Museum

1501 Crestline Drive, Suite 140

University of Kansas

Lawrence, Kansas 66049-2811

United States

\section{Subject Editor:}

Prof. Dr. H. H. Dathe 